\title{
Control Development and Modeling for Flexible DC Grids in Modelica
}

\author{
Andreas Olenmark ${ }^{1} \quad$ Jens Sloth $^{2} \quad$ Anna Johnsson $^{3} \quad$ Carl Wilhelmsson $^{3}$ Jörgen Svensson ${ }^{4}$ \\ ${ }^{1}$ One Nordic AB, Sweden, andreas.olenmark@one-nordic.se. \\ ${ }^{2}$ Gothia Power, Sweden, jens.sloth@gohiapower.com \\ ${ }^{3}$ Modelon AB, Sweden, carl.wilhelmsson@ modelon.com \\ ${ }^{4}$ Industrial Electrical Engineering and Automation (IEA), Lund University, Sweden, jorgen.svensson@iea.lth.se
}

\begin{abstract}
This article presents a way of implementing different control strategies for power electronic converters in the Modelica modeling language. The different control modes were fitted into flexible models that could be interconnected in various power grid topologies. The power grid examples were controlled and kept stable during various load scenarios, using the developed controlled converter models. The work was performed using the Modelica tool Dymola. Modelica is an equationbased object-oriented modeling language. Electrical components in the Electric power library (EPL) from Modelon were used to model power electronic units, grids and other electrical infrastructures. The outcome of this effort was simulation results which clearly demonstrate that the developed controllers enable scalable and controllable DC power grids.
\end{abstract}

Keywords: $\quad H V D C$, smart grids, converter control.

\section{INTRODUCTION}

The need for electrical energy is ever increasing and an increasing amount of the consumed energy is generated by renewable energy sources, even local and small power generators. In practice this means that the power distribution networks needs to be able to handle more power flux scenarios than they used to. This applies to electrical grids of all sizes whether it is a large national grid or a smaller household grid. The term "Smart Grids" is commonly used for these types of more flexible power grids. Common for these grid setups are that several units are coupled together and they need to be intelligently controlled to be able to keep the grid operational in the desired voltage level. The control units are power electronic devices e.g. converters which can operate either on alternating current (AC) or in direct current (DC). These units are fast enough so that they supply sufficient grid controllability. The converter needs to be able to transform AC from an $\mathrm{AC}$ power source to a DC grid or consumer, and vice versa. It also needs the ability to control power flow, voltage, current etc. This work accounts for a simulation model of flexible size which implements these devices. By modeling these converters and grids, different applications where these grids are used can be designed, simulated and studied.

\section{CONVERTER CONTROL}

Power electronic converters are used for many different applications such as AC/DC transformation, DC/DC conversion, electrical drives, etc. Semiconductor based converters features high control bandwidth and high energy conversion efficiency and is therefore an important component in modern electrical grids.

\subsection{THREE PHASE CONVERTER}

A three phase converter consists of six transistors (most commonly IGBT transistors), in parallel with each transistor there is a freewheeling diode connected (see Figure 2.1). The converter can be divided into three transistor half-bridges where each can be viewed as a switch. The diodes are needed to provide a path for the inductor currents when the transistors switch off. Pulse Width Modulation (PWM) is used to form a switch pattern which in turn creates a controllable output voltage. It is hence possible to control e.g. specific machines, eliminate harmonics when connected to the utility grid or uninterruptable power supplies (UPS). 


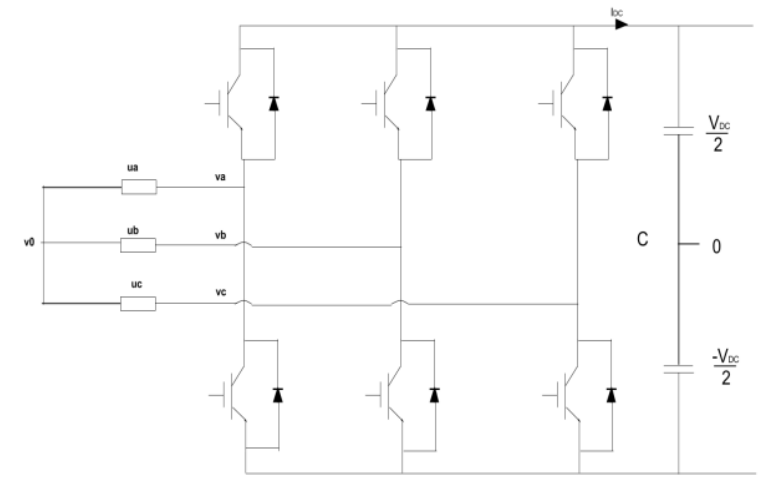

Figure 2.1 The electric schematic of the three phase converter connected to a load.

\subsection{ACTIVE FRONT END (3-PHASE CONVERTER)}

Usually, power electronic devices are supplied with DC voltage, conventionally obtained by rectifying the grid voltage using a diode or a thyristor rectifier bridge. The drawback with these rectifiers is that they introduce harmonic content in the current drawn from the grid and also lower the power factor due to its nonlinear properties. This result in a decrease in the power transferred across the line.

An active front end (AFE) is a three phase converter connected to the utility grid on one side and a DC grid on the other (see Figure 2.2). It has an inductance placed between the converter and the grid to provide voltage boosting, as well as to filter the currents. Capacitors are placed on the DC side to provide energy storage and to smooth the DC voltage. An AFE can be seen as a 4 quadrant DC/DC Boost Converter meaning that it can boost up the DC voltage to desired level and that it allows for power flux in both directions through the AFE (Carlsson, 1998).

By controlling the switching of the transistors the currents passing through the inductors are altered, hence the output DC voltage can be controlled. At the same time as the currents can be modulated to eliminate harmonics and to keep the power factor equal to one.

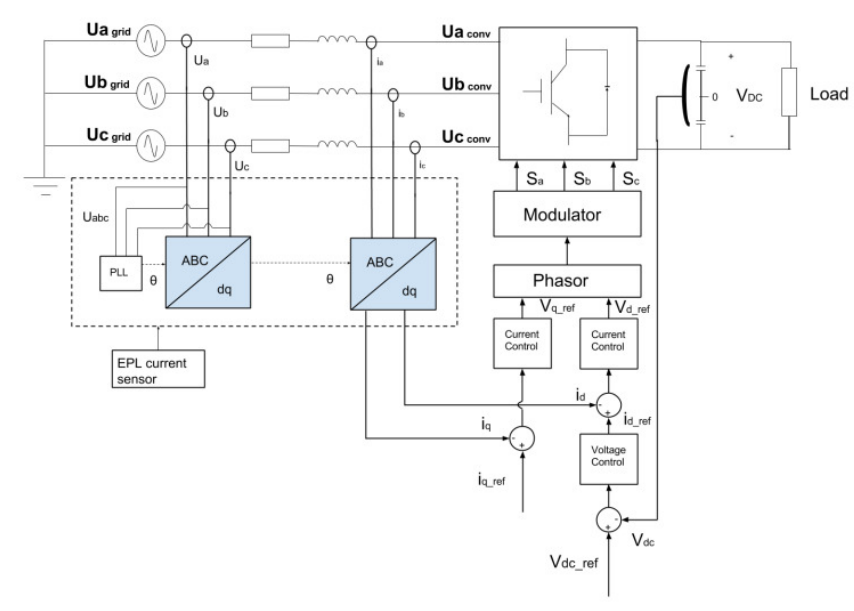

Figure 2.2 The AFE connected to the utility grid with DC voltage control.

The three-phase currents are controlled by applying the Park transformation to the currents, converting them into $d q$ coordinates. The active and reactive power can then be expressed in terms of the grid voltage and current and can be controlled separately.

$\left\{\begin{array}{l}P=\operatorname{Re}\left\{e_{d q} \cdot i_{d q}{ }^{*}\right\}=e_{d} i_{d}+e_{q} i_{q} \\ Q=\operatorname{Im}\left\{e_{d q} \cdot i_{d q}{ }^{*}\right\}=e_{q} i_{d}-e_{d} i_{q}\end{array}\right.$

Since the grid voltage is aligned with the $\mathrm{d}$-axis it means that $e_{q}=0$ and by controlling $i_{q}$ to zero the reactive power becomes zero.

$P=\operatorname{Re}\{S\}=e_{d} i_{d}$

$\mathrm{Q}=\operatorname{Im}\{S\}=0$

The power factor is defined as $\cos \theta$ and unity power factor occurs when $\cos \theta=1$ since:

$$
\begin{aligned}
& \theta=\arctan \left(\frac{Q}{P}\right) \\
& Q=0 \rightarrow \theta=0 \rightarrow \cos (0)=1
\end{aligned}
$$

Thus by controlling the $d q$ current separately unity power factor can be achieved. (Sanjuan, 2010)

\subsection{POWER CONTROLled AC/DC CONVERTER}

Power can also be controlled using a three phase converter, since the transformed currents affect the active and reactive power. Using a three-phase converter with a structure as in Figure 2.3, the active and reactive power can be controlled. 


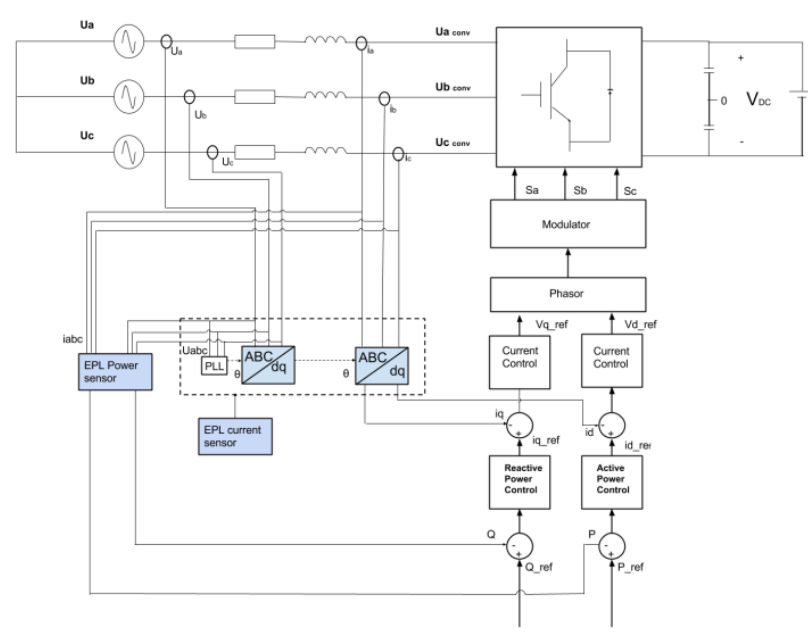

Figure 2.3 an illustration of the implemented power controller. The control logic implemented is a cascade controller, the outer loop controls power and the inner loop current.

\subsection{DROOP CONTROLLED AC/DC CONVERTER}

A combination of power and voltage control is called droop control. Droop control is in this work used to ensure voltage stability of the internal DC grid if, for some reason, the primary voltage source is disconnected or malfunctioning. The errors of the power and voltage are added together and the quantity which deviates most from its reference is subject of control, this can be seen in equation (8). By adding weights to the errors the droop control is achieved. The setup for this control strategy is shown in Figure 2.4. $e_{p-\text { controller }}=e_{V_{-} D C} \cdot k_{1}+e_{P} \cdot k_{2}$

Where

$\left\{\begin{array}{c}e_{V_{-} D C}=V_{D C_{-} r e f}-V_{D C} \\ e_{P}=P_{\text {ref }}-P\end{array}\right.$

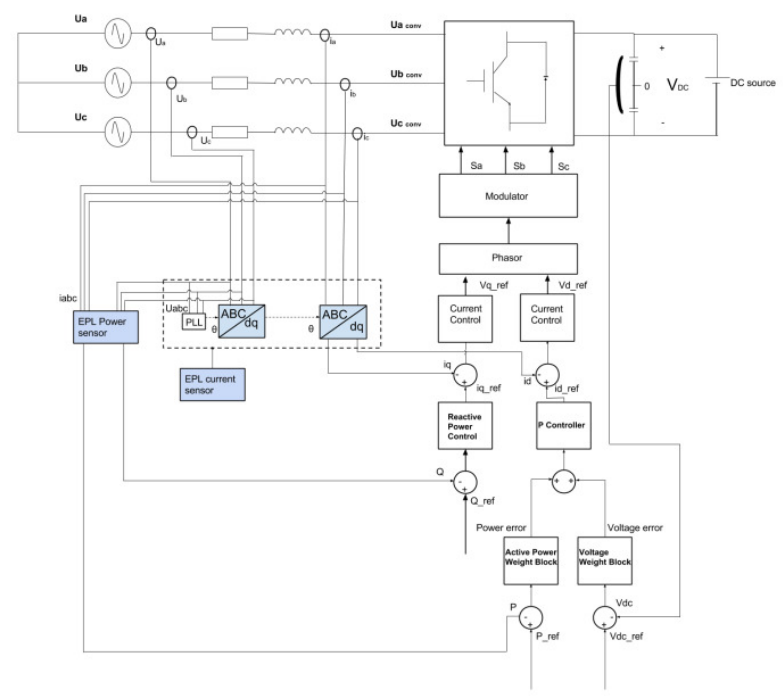

Figure 2.4 droop control structure.

\section{EXPERIMENTAL SETUP}

The models of the different kinds of power electronic converters were put together using Modelica and Dymola. The control logic of the converter models were made using infrastructure from the Modelica standard library (MSL). In order for the converter models to be flexible, to operate in different control modes and at different power levels, a converter component with interchangeable control schemes was constructed. The flexiblecontrol converter offers the possibility to choose between voltage, power or droop control. Depending on which type of grid that needs to be simulated, different power and voltage levels need to be selected in the component. The flexible-control converter model can easily be set up and parametrized using records.

\subsection{GRID SCENARIO SETUP}

To evaluate the converter and grid models, different scenarios were developed. E.g. a DC grid consisting of several converters connected in parallel (Multi Terminal Direct Current, MTDC), and nets with only two converters connected together. The converters were always connected with each other Back-to-Back, regardless of the amount of devices. In every system there had to be at least one converter responsible for keeping a constant DC voltage level on the DC grid. The one controlling the DC voltage is called master terminal and all other terminals are called slave terminals. The slave terminals were responsible for controlling power to the different sub units. The master terminal was the 
one maintaining power flow balance in the DC grid (Haileselassie, 2012).

\subsection{MULTI-TERMINAL HVDC SCENARIO}

The first grid examined was a MTDC grid for High Voltage Direct Current (HVDC). In this high voltage scenario example four multi controlled converters were connected in parallel and an AFE controlling the DC voltage was connected to the utility grid. The DC voltage level was set to be $130 \mathrm{kV}$. The converter components, intended to be connected to different generators, e.g. hydro-power plants or wind-power plants, were set to perform power control. The generators and the utility grid were represented by AC sources with $50 \mathrm{kV}$ line-line voltage, operating at $50 \mathrm{~Hz}$. The total maximum power of the generators was assumed to be 400 MW, $250 \mathrm{MW}$ for the two wind-power plants and $150 \mathrm{MW}$ for the hydro-power plant. The wind power plants were set to generate full power initially and then vary its output slowly according to a low frequency sinusoidal reference. The output of the larger of the two wind-power plants varied between 80-150 MW, with a frequency of $0.01 \mathrm{~Hz}$. The output of the smaller wind-power plant varied between 60-100 MW with frequency $0.05 \mathrm{~Hz}$. The hydro-power plant generated full power and was shut down periodically. This behavior was achieved by using square wave as input to the power reference of the converter connected to it. The Modelica implementation of the grid setup can be found in Figure 4.1.

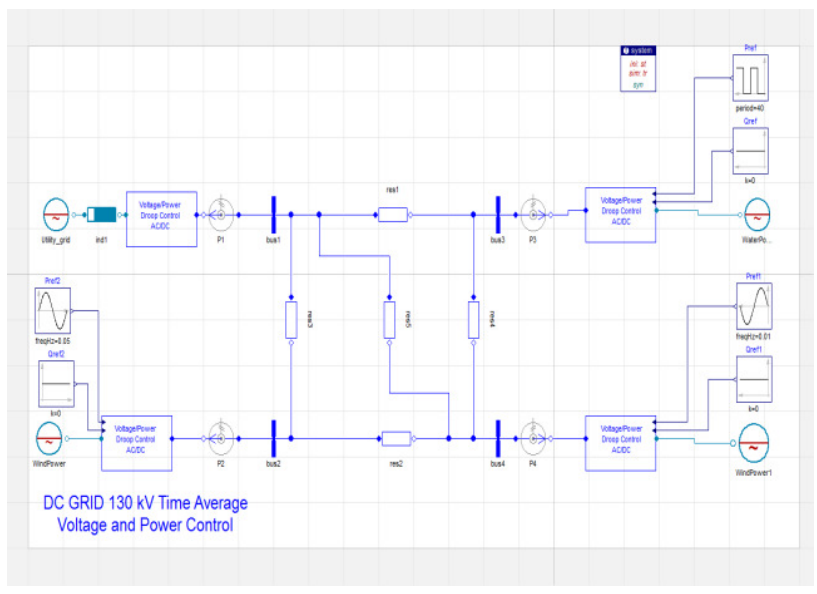

Figure 3.1 Modelica implementation of the HVDC grid

\subsection{Household With Local Power PRODUCTION}

The second grid topology which was studied was developed to mimic a typical household with local power production. Two wind turbines were connected to the DC grid as well as a model of a "smart" house. The wind turbines had capacity of 4 $\mathrm{kW}$ each. The AC distribution grid was connected to the DC grid through an AC/DC converter. The converter was set to control DC voltage to $1.5 \mathrm{kV}$. The AC distribution grid was represented by an AC source operating at $50 \mathrm{~Hz}$ and $400 \mathrm{~V}$ line-line. Additionally a solar power plant, represented by a DC source with voltage $100 \mathrm{~V}$, was connected to the DC grid through a power controlled DC/DC converter. The power "generated" by the solar plant varied according to a sinusoidal between $0-2 \mathrm{~kW}$. The Dymola implementation of the grid setup can be found in Figure 4.2.

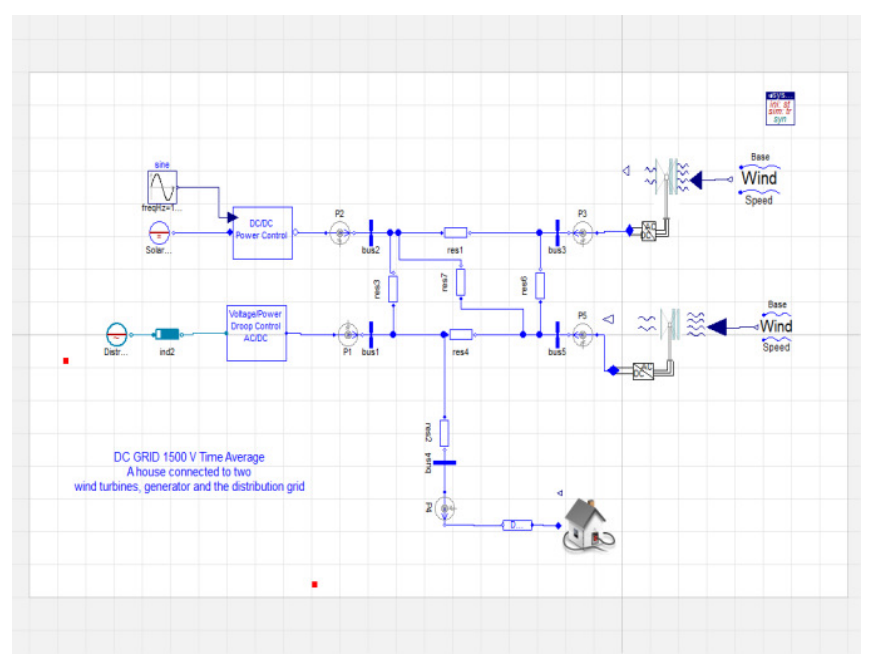

Figure 3.2 The grid setup for the DC grid with Smart Grid Library and Wind Power Library models connected

\section{Results}

\subsection{MULTI-TERMINAL HVDC SCENARIO}

The power-controlled AC/DC converters should deliver the power generated by power sources to the internal DC grid. The voltage at the internal DCgrid/utility-grid connection point was to be kept constant. The power generated by the power plants was to be fed to the utility grid. 

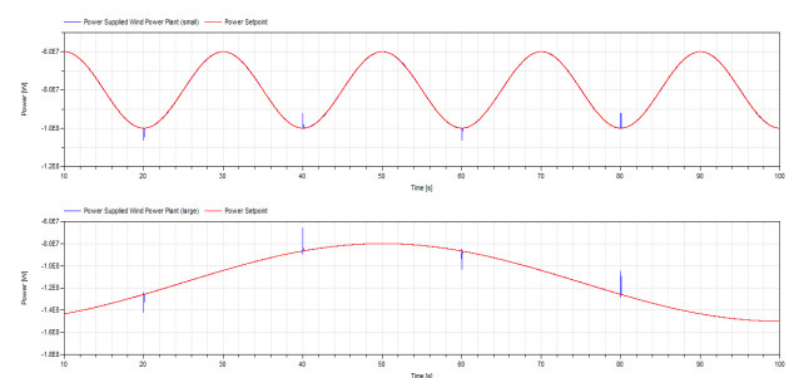

Figure 4.3 The power generated by the wind power plants fed to the internal DC grid,250MW (top) and $400 \mathrm{MW}$ (bottom).
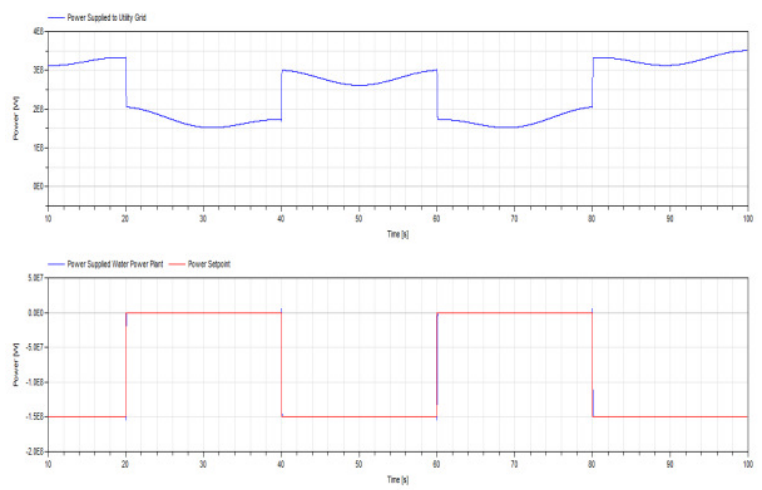

Figure 4.4 The power generated by the hydro power plant (bottom) and the power supplied to the utility grid (top).
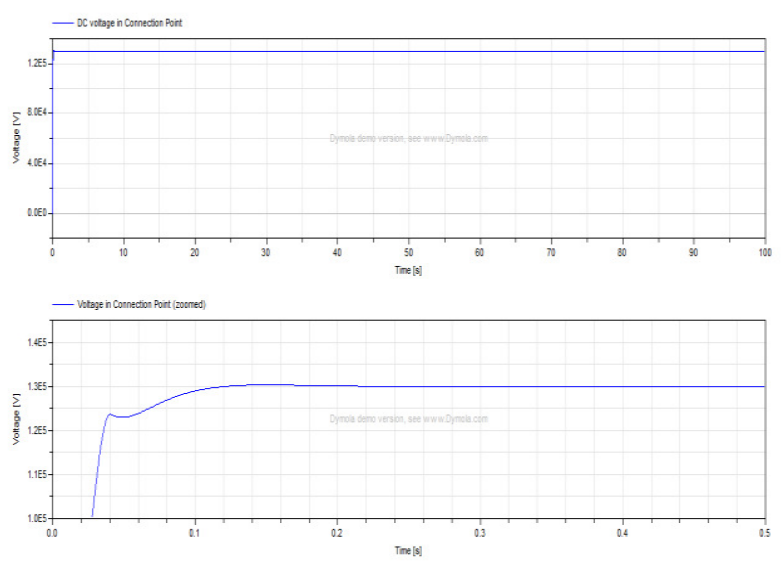

Figure 4.5 the voltage at the connection point of the DC grid to the utility grid (zoomed in bottom).

The power which was generated by "wind-power" and fed to the internal DC grid can be found in Figure 4.3. Figure 4.4 shows corresponding for the hydro power plant. The limiting factor was the speed of the power controller as visible in Figure 4.4, where a large change in power control reference value takes place momentarily. The power controller responded very quickly to this change and it hence proved adequate. Sudden changes which were made to the hydro power plant reference proved to affect the wind power plants. Sudden changes in power will of course affect the current flowing through the circuit and thus the power which had to be supplied by the power controlled converter connected to the wind power plants. Even though there was an undershoot occurring the recovery was swift and the system maintained stability.

The voltage in the connection point between the utility and internal DC grid was kept throughout the simulation and was not affected considerably by the rapid changes in power flow as can be seen in Figure 4.5 .

The generated power was supplied to the utility grid as visible in Figure 4.4.

Since the resistance of transmission lines is large for longer lines, a considerable loss in power will occur while putting current through long transmission lines. The losses can be minimized by raising the voltage of the DC grid, but this will put a larger demand on the power electronic equipment and also add to the investment cost of this equipment (Alaküla, 2011).

To keep the power balance the voltage of the internal DC grid voltage should be kept constant when changing the load characteristics and with varying power supply. The power supplied should be consumed by the load when load is active. The remaining power should be fed to the AC distribution grid. On the other hand, the AC distribution grid supplies power when the local generation is insufficient.
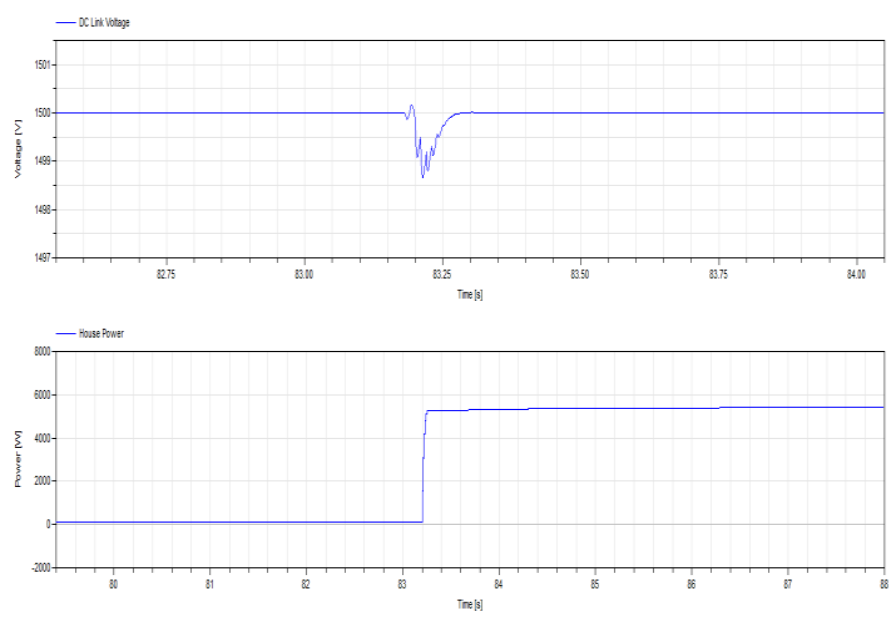

Figure 4.1 The voltage (top) of the DC grid reacting on a sudden change in power consumption (bottom) in the load. 

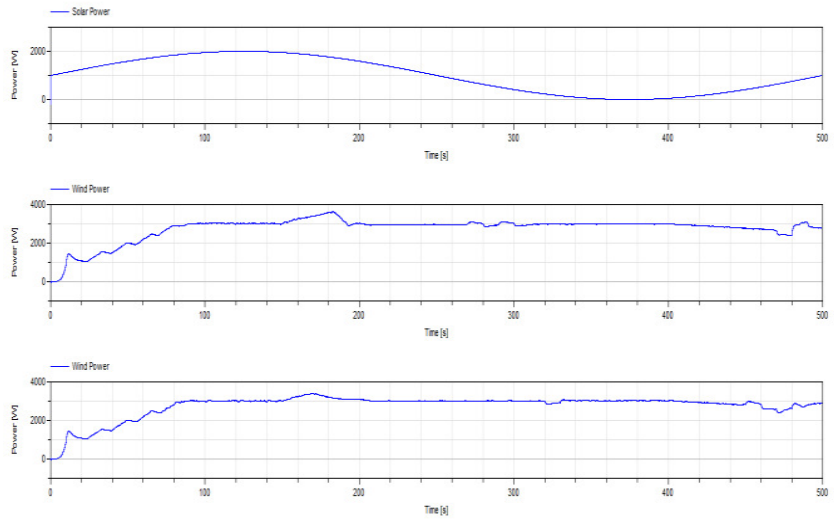

Figure 4.2 The power supplied by the generators, in the wind power plants and for the solar power plant (top)
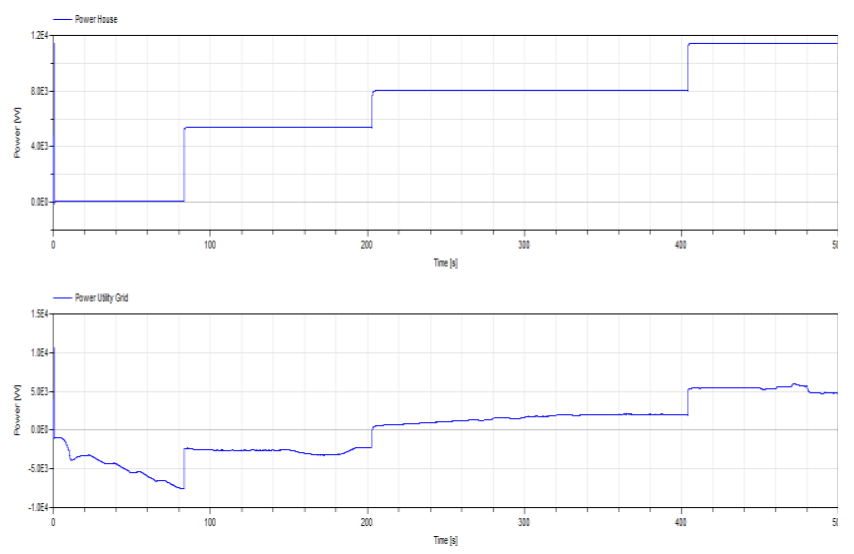

Figure 4.3 The power consumed by the load (top) and the power supplied to/consumed from the AC distribution grid

\subsection{HOUSEHOLD WITH LOCAL ENERGY Production}

The voltage of the DC grid could be kept at $1.5 \mathrm{kV}$ as can be seen in Figure 4.6. When the load was changed the voltage of the DC grid undershoots, it was however quickly brought back to the set point of $1.5 \mathrm{kV}$ by the voltage controller. The largest part of the power that was consumed by the load was generated by the local wind and solar power plants, see Figure 4.7 and 4.8. The excess power was fed to the AC distribution grid as can be seen in Figure 4.8. In the same figure it is also shown that the $\mathrm{AC}$ distribution grid supplies the remaining power consumed by the load when local production units were unable to keep power balance.

\section{CONCLUSIONS}

The main purpose with the work undertaken was to implement a scalable, flexible and controllable grid. The term scalable implies that the grid could have been used in many different voltage and power levels, meaning that the grid could represent different applications.

As seen from the results the converters and the implemented control strategies maintains grid voltage and power flow as expected. This shows that the models can be interconnected and works in a rather stressed environment. It also shows that an arbitrary grid can be constructed and simulated using these flexible models for system and grid analysis. The two different grid models show the flexibility of the constructed examples. In addition the constructed models were tested together with external library models such as wind power models and energy consumers with local generation. This demonstrates compatibility with other libraries.

The compatibility with other libraries enables a further development of the grid models. In this article two examples are demonstrated but these models provides the opportunity to simulate other scenarios. For example internal grids in vessels, charging stations for electric vehicles, internal grids in vehicles or the internal grid of several wind power plants can be simulated using these flexible models.

The opportunity is given to implement more efficient systems and to evaluate new ideas. The models enable integration of new technologies for renewable power generation and efficient distribution of power. These models provide the opportunity to simulate and, in extension, realize smart grid implementations.

Neither switching nor thermal losses were taken into account here. In order to get more accurate and realistic results losses should be included in the analysis. The EPL components used in the construction of the models support these kinds of losses, enabling these effects is however regarded as future work.

\section{NoMenClatuRE}

$\vec{e}_{d}-d$-component of the grid voltage

$\vec{e}_{q}$ - q-component of the grid voltage

$\vec{e}_{d q}-$ Grid voltage in $d q$ coordinates

$U_{d c}-D C$ link voltage of the three phase converter 
$v_{a}$ - Output voltage of the three phase converter phase a

$v_{b}$ - Output voltage of the three phase converter phase $b$

$v_{c}$ - Output voltage of the three phase converter phase $c$

$v_{0}$ - Zero potential of the three phase converter

$u_{\alpha}$ - Phase voltage expressed in the real component of the complex $\alpha, \beta$ vector.

$u_{\beta}$ - Phase voltage expressed in the imaginary component of the complex $\alpha, \beta$ vector.

$u_{a}$ - Voltage over the load of the three phase converter output phase a

$u_{b}$ - Voltage over the load of the three phase converter output phase $b$

$u_{c}$ - Voltage over the load of the three phase converter output phase $c$

$|\vec{x}|$ - Magnitude of the maximum output voltage vector of the three phase converter

$i_{d}$ - $d$-component of the $d q$ current vector $i_{q}$ - q-component of the $d q$ current vector

\section{REFERENCES}

M Alaküla, P Karlsson, "Power Electronics: Devices, Converter, Control and Applications", Department of Industrial Electrical Engineering and Automation.

M. Alaküla, L. Gertmar, O. Samuelsson, "Elenergiteknik", Lund, Sweden, Lunds Tekniska Högskola, Department of Industrial Electrical Engineering and Automation, 2011

A. Carlsson, "The back to back converter control and design", Lund, Sweden, Department of Industrial Electrical Engineering and Automation Lund Institute of Technology, May 1998.

T. M.Haileselassie; "Control, Dynamics and Operation of Multi-terminal VSC-HVDC Transmission Systems", Norwegian University of Science and Technology Department of Electric Power Engineering Trondheim December 2012.

S. L. Sanjuan, "Voltage Oriented Control of Three-Phase Boost PWM Converters Design, simulation and implementation of a 3-phase boost battery charger". Department of Energy and Environment, Division of Electric Power Engineering CHALMERS UNIVERSITY OF TECHNOLOGY, Göteborg, Sweden, 2010. 